\title{
Knowledge Sharing Behavior in Homeland Security - The Role of Trust, Technology, and Expectations
}

\author{
Evette Maynard-Noel \\ Cybersecurity and Infrastructure Security Agency \\ U.S. Department of Homeland Security \\ Evette.Maynard-Noel@cisa.dhs.gov
}

\author{
Souren Paul \\ College of Informatics \\ Northern Kentucky University \\ Souren.Paul@gmail.com
}

\begin{abstract}
This study focused on the knowledge sharing of employees at homeland security. In this study we developed and tested a theoretical model on the factors that influence employees' attitude, intention, and behavior to share knowledge. We relied on the theory of reasoned action and media synchronicity theory to build our theoretical model. We found support for most of our hypotheses in this study which are consistent with prior studies on knowledge sharing. In particular, we found that trust had a positive relationship with the attitude to share knowledge. Another important finding is the role of information and communication technology (ICT) in knowledge sharing in homeland security. We found that ICT to support processing of information strengthened individual employees' intention to share knowledge while the technology to support transmission of information facilitated knowledge sharing behavior.
\end{abstract}

\section{Introduction}

The tragic events of September 11, 2001 placed greater emphasis on collecting and sharing data, information, and knowledge involving risks and threats to national security. Legislative mandates on information and homeland security [18, 26, 25, 27] and Presidential Directives and Executive Orders [19, 20] call for federal agencies to develop information and knowledge sharing capabilities to not only ensure that the right information gets to the right people, but that it also facilitates the appropriate knowledgebased decisions at the right time.

Accomplishing this mission requires employees to have access to specific information and knowledge, as well as the ability to share those not only with other federal agencies, state and local governments, the private sector, and partners but internally as well. Even with the growth of technology that enables organizations to access distributed resources and acquire knowledge in different ways, if employees' behavior does not change, and they lack the motivation and methods to share knowledge, it is challenging to share the decisions [43].

Prior research has predominately focused on private sector companies, rather than on public or federal government sector, and the existing literature supports a range of knowledge management definitions with varying levels of importance [4, 7, 8]. Limited research exists on the management and sharing of knowledge in the federal government, and little attention has been paid to the role of motivation factors that influence employees' attitudes and intentions to share knowledge [8].

Additionally, the use of technology and its influence on employees' intentions and behavior to share knowledge in a homeland security organization within the United States has also received minimal attention. In this research, we attempt to address this gap by focusing on the factors that may influence knowledge sharing behaviors of employees in a Federal Government organization of the United States. Based on the review of prior literature, we identify the key constructs that may shape knowledge sharing in government organizations.

We focus on how employee attitude, intention, and information and communication technology (ICT) usage influence knowledge sharing in homeland security. In addition, we also examine the factors that influence the attitude of employees to share knowledge in these organizations. The primary research questions in this study are:

- $\quad$ RQ1: Do the attitude and intention influence knowledge sharing behavior of employees in homeland security organizations?

- RQ2: What role does IT usage play in shaping knowledge sharing intention and behavior of employees in homeland security organizations? 


\section{Literature review and theory development}

In this section, we first discuss the theoretical underpinning of our research model. We draw on the theory of reasoned action (TRA) to suggest that the knowledge sharing behavior of employees will depend on their pre-existing attitudes and intentions. In the process of sharing knowledge, employees get engaged in shared pattern of coordinated behavior through the use information and communication technology (ICT). Some ICTs facilitate transmission of information while others support processing of information. We rely on Media Synchronicity Theory (MST) to propose how these technologies influence the knowledge sharing behavior and intentions of employees. We discuss TRA and MST to lay the theoretical foundation of this research. Following our discussion of the theoretical foundations, we elaborate the constructs of our study, and build our research model which is presented in figure 1.

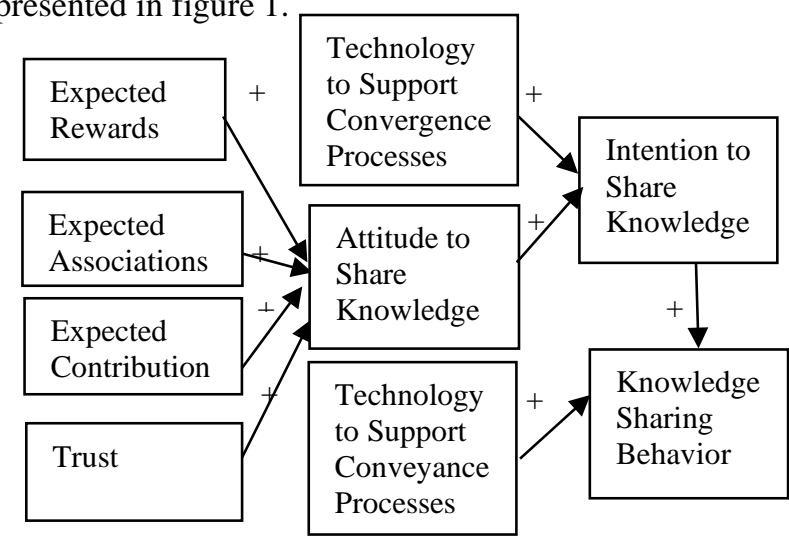

Figure 1. Proposed research model.

\subsection{Literature review and theory development}

\section{Theory of Reasoned Action (TRA)}

TRA attempts to explain how humans behave based on their pre-existing attitudes and intentions. Knowledge sharing practices "can be studied by applying the TRA, wherein attitudes are predicted by evaluating an individual's intention to perform certain behaviors” [36] (p. 15). An individual's intention to act or perform a task is determined by the individual's attitude toward the task [5]. In a knowledge sharing context such as that presented in this study, an individual may demonstrate more knowledge sharing behavior if they exhibit a positive attitude toward knowledge sharing. This attitude towards the task directly affects a person's intention toward performing a task $[7,8,9]$.
One critical aspect of TRA is the underlying assumption that people, being rational beings, are in control of making their own choices about their behaviors, and-individual intentions are determined by an individuals' attitude about the behavior [21]. Given the fact that knowledge sharing is a voluntary behavior, this also makes TRA a relevant model in the study of knowledge sharing [7, 28].

\subsection{Attitude toward knowledge sharing}

Attitude towards knowledge sharing is formed from behavioral beliefs and refers to the degree of positive/negative feelings an individual has towards the intention to share knowledge [32]. Bock and Kim [7] suggest that expected rewards, expected contributions, and expected associations shape attitude towards knowledge sharing [7].

Knowledge sharing involves social interaction among people. Two principal theories that explain the social interaction of people are economic exchange theory and social exchange theory. According to the economic exchange theory, individuals will behave by rational self- interest. Thus, knowledge sharing will occur when it is determined that rewards for sharing exceed its costs to share $[12,31]$. That is why many researchers have emphasized incentive systems for successful knowledge management.

Expected rewards, defined as "the degree to which one believes that one can receive extrinsic incentives based on one's knowledge sharing” [7] (p. 1116), is believed by many to be one of the most important motivating factors for knowledge sharing. Thus, expected reward implies that employees would develop a more positive attitude toward knowledge sharing if they believe they will receive some type of monetary reward, promotion, or educational opportunities from their knowledge sharing [36, 52].

Kling and Lamb [34] found that rewards such as incentive and recognition influenced the user's use of technology to share knowledge. Accordingly, expected reward implies employees would develop a more positive attitude toward knowledge sharing if they believe they will receive some type of monetary reward, promotion, or educational opportunities from their knowledge sharing, thereby encouraging knowledge sharing. The absence of clear reward and recognition systems may frustrate employees and interfere with existing or potential knowledge sharing [42]. If employees believe they will receive extrinsic benefits such as monetary rewards, promotion, or educational opportunity from their knowledge sharing, they will develop a more positive attitude toward knowledge sharing [53]. Hence: 
H1: Expected rewards will have a positive effect on the employee's attitude toward knowledge sharing.

Expected contributions, on the other hand, is defined as "the degree to which one believes that one can improve the organization's performance through one's knowledge sharing” [7] (p. 1116). An employee's judgment of their own capabilities, called self-efficacy, refers to the idea that if employees believe they could make contributions, they will develop a more positive attitude toward a behavior [6], in this case, the employee would have a more positive attitude toward knowledge sharing, and are generally self- motivated to do so [10]. Hence:

H2: Expected contribution will have a positive effect on the employee's attitude toward knowledgesharing.

Expected associations constitute is another significant determinant of an individual's attitude toward knowledge sharing [7]. Expected associations are defined as "the degree to which one believes one can improve the mutual relationship through one's knowledge sharing" [7] (p. 1116).

Expected associations occur through social exchanges. Social exchanges are personal and tend to generate personal connections between individuals, such as gratitude and trust. Through expected associations, assumptions can be made that employees may be able to maintain or improve relationships through social interactions that could include mentoring and coaching with other employees to offer their knowledge, with the expectation of reciprocal benefits through knowledge sharing [24].

When employees believe they can improve relationships with other employees by offering their knowledge, they develop a more positive attitude toward knowledge sharing [7, 40, 53]. Hence:

H3: Expected association will have a positive effect on the employee's attitude toward knowledge sharing.

\subsection{Trust}

Researchers suggest that trust plays a significant role as to whether knowledge sharing occurs in organizations [41]. Trust is when one party expects that a second party will do what it has promised, without being opportunistic about it. Hsu et al. [29] defined trust as "an implicit set of beliefs that the other party will behave in a dependent manner and will not take advantage of the situation” (pg. 154).

Trust is a crucial determinant of employee participation and sharing knowledge [51]. Additionally, trust is considered one of the most important motivators for successful knowledge sharing process, one of the necessary first steps to effective knowledge sharing [51] and is noted to increase goodwill among employees [35]. While it is expected that there are varying levels of trust between employees at different levels of organizations, in an organization with a national security mission, the perception of high levels of trust is expected to facilitate the sharing of knowledge.

In an organizational context, learning behaviorsuch as seeking feedback or learning from one's mistakes, asking for help, talking about errors, and experimenting - fosters a safe feeling. The absence of that safety, which may cause underreporting of incidents, leads to mistaken perceptions of the threats and security situation of the organization [38]. These mistaken perceptions include the fear of being viewed as disloyal or untrustworthy and being punished publicly or privately for any mistakes made, which causes sensitivity and fear of coming forward [50].

In a thriving sharing environment, however, any mistake would be an opportunity to learn from failure, where the lessons-learned from what works and what does not work is considered to be valuable. In instances where employees trust their supervisors and are satisfied with them, they show increased innovative behavior and were likely to help their coworkers. Therefore, when employees trusted their supervisors, they were likely to share knowledge [61].

Fueled by regulatory compliance and pressure from lawmakers, reports published by the United States GAO acknowledged improvements made by DHS in their sharing efforts and recommended developing strong partnerships for information and knowledge sharing [60].

The existence of trust and the formation of trust, whether in actions and behaviors, intentions and perceptions, or ideas and beliefs, affect knowledge sharing and the willingness or motivation to share on individual and organizational levels [38, 39]. Trust "develops from having some familiarity and prior interaction" [38] (p. 8) and "is both an initial condition for the formation of a relationship as well as the result of positive interaction" [41] (p. 297). The literature also suggests that that managers and leaders in the government public sector "commit to promoting informal and formal networks and knowledge-oriented management practices" [33] (p. 256). Cultivating higher levels of trust can lead to better knowledge sharing, shared goals, and lower transaction costs, promoting more active and trustworthy knowledge sharing behavior among employees, enhancing communication speed by empowering members to share their knowledge (pg. 251). Hence: 
H4: Trust will have a positive effect on the employee's attitude toward knowledge sharing.

\subsection{Knowledge Sharing Intention}

Behavioral control describes the individual's perception of the extent they have control over the specified behavior [3]. Knowledge sharing is the specified behavior, and that behavior is affected by an individual's confidence in the opportunities and resources that enable them to share their knowledge [1, 32, 37, 59]. Attitudes influence a person's evaluation or perception of behavior and are a significant part "of the cognitive system and have the potential to influence the intention to share knowledge" [59] (p. 614).

TRA suggests that attitudes determine intention, and the greater or more favorable the attitude toward the action, the greater or more favorable the intention toward the behavior [5]. Hence:

H5: Attitude toward knowledge sharing will positively influence the intention to share knowledge.

Knowledge sharing process involves the development of shared understanding which is achieved through transmission of information and processing of information. Each employee develops an interpretation of a situation through the processing of information. Use of the technology to support processing of information generates confidence that an employee has control over the knowledge sharing behavior. Hence:

H6: Use of technology to support processing of information will have a positive effect on the intention to share knowledge.

\subsection{Knowledge Sharing Behavior}

Several studies $[8,10,62]$ used the TRA or its extension, the theory of planned behavior, to explore knowledge sharing. According to the TRA, the behavior is determined by sharing attitudes toward sharing, and the best predictor of behavior is intention [52]. Intentions are formed by the motivational factors that affect behavior; they are indicators of people's willingness to try hard [1]. Individual intention to share knowledge is a determining factor of desired individual behavior [49]. Intention to share knowledge can have a significant effect on knowledge sharing behavior. Findings in earlier studies show the positive effect of intention on knowledge sharing behavior [59]. Hence:

H7: Employee's positive intentions to share knowledge positively affect knowledge sharing behavior.

In addition to having the intention to share knowledge, we expect that the use of ICT plays a role in shaping knowledge sharing behavior. Individual employees develop an interpretation of a situation through the processing of information. Individual interpretations are exchanged and discussed to reach a common understanding of a situation which is an essential aspect of knowledge sharing behavior. The exchange of information in any organization is facilitated through the use of ICT. In particular, technologies, such as video conferencing, instant messaging support high level of information transmission. Hence:

H8: Use of technology to support transmission of information will have a positive effect on knowledge sharing behavior.

\section{Research Method}

Most prior studies of knowledge sharing have predominately focused on private sector companies, rather than the public or federal government sector. We base our study on the employees in homeland security. We conducted a web-based survey to collect our data. Due to the geographically dispersed nature of the workforce, paper-based surveys would have posed a challenge. Web- based surveys are widely used in academic, behavioral research, and offer multiple benefits over paper-based surveys, including efficiency and cost-effectiveness [57]. In addition to being easy to administer, web-based surveys offer a wider reach, faster implementation, and distribution time, and offers convenience to the respondent, making a web-based survey a more appropriate choice over interviews or observations [13].

We administered the survey via SurveyMonkey, an online survey creation and administration platform. The participants were informed that the survey was voluntary, and that all information would be kept confidential. Participants were also informed of the expected amount of time they would need to complete the survey. The survey was scheduled to remain active for 30 days. Within four days of the closing date of the survey, follow-up e-mail messages were sent, notifying the community that the survey link would be closing in 4 days.

\subsection{Sample Design}

The population under investigation in this study was employees of the DHS. In its mission to keep the nation secure, DHS employs approximately 240,000 employees throughout the United States and its territories [64], which is an expansive membership. However, the largest concentration of DHS employees ( $12 \%$ or 24,000 employees) works in the 
National Capitol Region (NCR) [59]. An analysis using $\mathrm{G}^{*}$ Power 3.1.9.2 was conducted to determine the desired sample size for this study. The parameters of the power analysis were based on a multiple linear regression with a maximum of four predictors. The desired power and significance levels were .80 and .05 , respectively, per the recommendations of [11]. The potential for respondent accessibility limitations could have resulted in a required sample that exceeded the resources available to the researcher, based on the size of the population. Therefore, a medium or moderate expected effect size equal to .15 was used, resulting in an expected sample size of 84 for this study.

For this study, pre-notification, follow-up, and reminders messages were sent through direct solicitation emails by one of the researchers of this study. The survey was distributed in a population upwards of 240,000 or more individuals. The sample was chosen as a representation of the entire spectrum or population of employees in DHS. The expectation was for a low-to-medium level of engagement (response rate), and a medium or moderate effect size (f2).

\subsection{Operationalization of Variables}

We designed a survey instrument to measure the constructs of this study. The survey for this study was developed using previously validated survey instruments. We included items to measure expected rewards, expected associations, expected contributions, attitudes to share, intention to share [7]; trust and knowledge sharing [61]; and ICT usage [40]. In addition, we collected demographic information (such as, age, gender, nationality) and the data regarding the number of years of employment with the organization, education, and duty location, to determine representativeness of the population.

\subsection{Reliability and Validity}

A valid instrument measures what the researcher intends for it to measure. Validity is the ability of a researcher to draw valid and significant conclusions about a population from a data sample collected [13]. Reliability addresses the consistency within a constructor scale [49]. The internal consistency of items reflects the reliability of a measuring instrument. Internal consistency assures that the items within the construct or scale focus on the extent to which respondents are consistent in how they answer questions that are related to each other. Cronbach's alpha is used to assess the internal consistency reliability for reflective measures of the survey [54].
The Cronbach's alpha for internal consistency reliability in confirmatory research should be at least .70 [49].

Construct validity is defined as "the extent to which the results of a test are related to an underlying psychological construct” [45] (p. 116). Construct validity determines whether measures used are actual constructs describing the event and referred to how well the elements of a concept have been defined in the research or survey [48].

A cadre of experts was used to assess the face validity of the instrument. Their areas of expertise include business, IT, knowledge management, cybersecurity, law enforcement, critical infrastructure protection, and homeland security. These experts have taken part in different knowledge management activities in their daily job functions. Based on feedback from the expert panel, changes were made to the instructions and/or questions for clarity, structure, etc., as well as adjustment of the estimated completion time if necessary.

\subsection{Pilot Study}

Pilot studies are meant to reveal flaws and deficiencies in studies [15]. Participants of the pilot study used this interim instrument to ensure appropriate measures and clarity. This process ensured that the instrument met understandability, answerability, and readability requirements [22]. Pilot study participants were excluded from taking part in the formal study.

\subsection{Data Collection}

A formal study was conducted following the pilot study. A total of 393 respondents accessed the survey instrument. A total of 271 respondents or $68.96 \%$ completed the survey. Although this is not a high number of responses, there were a sufficient number of responses for this study. Data collection for the formal study was initially scheduled to take place over 30 days. The study, however, took place over 37 days from June 1, 2018, to July 7, 2018.

\section{Results}

Before conducting the primary analysis, the data were checked for missing responses. Cases with nonrandom patterns of missing data (i.e., several consecutive questions with missing responses) were excluded from the analysis.

\subsection{Descriptive Statistics}


The sample of 271 complete respondents had approximately equal numbers of women $(n=123$, $45.4 \%)$ and men $(n=128,47.2 \%)$. The majority of participants identified as White/Caucasian ( $\mathrm{n}=144$, $53.1 \%)$ and were born in the United States $(n=237$, 87.5\%). The largest proportion of participants were born in the 1960s ( $\mathrm{n}=66,24.4 \%$ ); on average the participants had 25.73 years of work experience (SD = 14.26), and the more mature participants were from the years between 1920 to 1969 and accounted for a little more than half of the population $(n=138$, $50.9 \%)$. For the largest proportion of participants, the highest level of education attained was a master's degree ( $n=93,34.3 \%$ ). Finally, the sample was split evenly between participants from the NCR ( $n=131$, $48.3 \%$ ) and participants outside of the NCR ( $\mathrm{n}=131$, $48.3 \%)$.

\subsection{Reliability and Validity Tests}

A Cronbach's alpha reliability analysis was conducted on each set of items comprising the study variables. The results of the reliability validity analyses are displayed in Table 1. Reliability exceeded .70 for all variables, which is the cutoff for acceptable internal consistency [23]. In order to test convergent validity, exploratory factor analyses were conducted for the items corresponding to each construct with a principal component analysis method of extraction and a varimax rotation. An exploratory factor analysis, with all items corresponding to the constructs, was conducted to test the discriminant validity of the constructs. Convergent and discriminant validities of the constructs were found to be satisfactory.

Table 1. Descriptive statistics and reliability coefficients for composite variables

\begin{tabular}{|l|c|c|c|c|c|}
\hline Variable & Mean & $\begin{array}{l}\text { Standard } \\
\text { Deviation }\end{array}$ & $\begin{array}{l}\text { Number } \\
\text { of Items }\end{array}$ & CA & $\begin{array}{l}\text { Factor } \\
\text { Loading }\end{array}$ \\
\hline $\begin{array}{l}\text { Expected } \\
\text { Rewards }\end{array}$ & 2.71 & 1.10 & 3 & 0.90 & $0.89-0.92$ \\
\hline $\begin{array}{l}\text { Expected } \\
\text { Contributions }\end{array}$ & 4.07 & 0.64 & 5 & 0.92 & $0.85-0.91$ \\
\hline $\begin{array}{l}\text { Expected } \\
\text { Associations }\end{array}$ & 3.87 & 0.72 & 5 & 0.91 & $0.81-0.89$ \\
\hline $\begin{array}{l}\text { Attitudes to } \\
\text { Share } \\
\text { Knowledge }\end{array}$ & 4.03 & 0.61 & 5 & 0.79 & $0.49-0.84$ \\
\hline Trust & 3.44 & 0.83 & 7 & 0.94 & $0.79-0.93$ \\
\hline $\begin{array}{l}\text { Intentions to } \\
\text { Share } \\
\text { Knowledge }\end{array}$ & 4.12 & 0.66 & 5 & 0.90 & $0.79-0.89$ \\
\hline $\begin{array}{l}\text { IT Type } \\
\text { Knowledge }\end{array}$ & 3.84 & 1.39 & 5 & 0.82 & $0.69-0.81$ \\
\hline $\begin{array}{l}\text { Knowledge } \\
\text { Sharing }\end{array}$ & 3.82 & 0.73 & 5 & 0.88 & $0.76-0.87$ \\
\hline
\end{tabular}

\subsection{Hypotheses Tests}

The hypotheses were tested through regression analyses with a level of significance of 0.05. Any weak significance level in the range of .05 to .10 was treated as suggestive of the nature of relationship between the variables.

Prior to conducting each regression, the assumptions of normality and homoscedasticity were tested. Multiple linear regression requires that the independent variables are not too highly correlated with each other (i.e., multicollinearity). This was tested by computing variance inflation factors (VIFs). We found that ensured that VIFs did not exceed 10 ensuring that multicollinearity was not an issue in this study [47].

Three multiple linear regressions were conducted to test the research hypotheses. The results of the regression predicting attitudes to share knowledge are presented in table 2. We find support for hypotheses 2, 3, and 4. Expected rewards is not found to have any significant relationship with attitude to share knowledge in our study.

Table 2. Results of regression analysis for attitude to share knowledge

\begin{tabular}{|l|l|}
\hline \multicolumn{1}{|c|}{$\begin{array}{c}\text { Independent } \\
\text { Variable }\end{array}$} & \multicolumn{1}{|c|}{$\begin{array}{c}\text { Attitude to Share } \\
\text { Knowledge }\end{array}$} \\
\hline Intercept & $2.005^{* * * *}$ \\
\hline Expected rewards & -0.009 \\
\hline Expected contributions & $0.155^{* * * *}$ \\
\hline Expected associations & $0.259^{* * * *}$ \\
\hline Trust & $0.187 * * * *$ \\
\hline R-Square & 0.3271 \\
\hline F & 26.37 \\
\hline Prob. (F) & $<.0001$ \\
\hline $\mathrm{N}$ & 262 \\
\hline & $\mathrm{H} 1=\mathrm{No} ; \mathrm{H} 2=$ Yes; \\
\hline Hypothesis Supported? & $\mathrm{H} 3=$ Yes; H4 = Yes \\
\hline$* \mathrm{p}<0.10 ; * * \mathrm{p}<0.05 ; * * * \mathrm{p}<0.01 ; * * * * \mathrm{p}<0.001$ \\
\hline
\end{tabular}

The results of the regression predicting intentions to share knowledge are presented in Table 3. We find that both the attitude to share knowledge and the use of technology that supports processing of information have significant relationship with the intention to share knowledge. Thus, we find support for both hypotheses 5 and 6 .

The results of the regression predicting knowledge sharing behavior are presented in Table 4. We find that both the intention to share knowledge and the use of technology that supports transmission of information have significant relationship with the intention to share knowledge. Thus, we find support for both hypotheses 7 and 8 . 
Table 3. Results of regression analysis for intention to share knowledge

\begin{tabular}{|l|l|}
\hline \multicolumn{1}{|c|}{$\begin{array}{c}\text { Independent } \\
\text { Variable }\end{array}$} & \multicolumn{1}{|c|}{$\begin{array}{c}\text { Attitude to Share } \\
\text { Knowledge }\end{array}$} \\
\hline Intercept & $1.761^{* * * *}$ \\
\hline Attitude to share knowledge & $0.568 * * * *$ \\
\hline $\begin{array}{l}\text { Use of ICT that supports } \\
\text { processing of information }\end{array}$ & $0.029 * *$ \\
\hline R-Square & 0.3365 \\
\hline F & 45.13 \\
\hline Prob. (F) & $<.0001$ \\
\hline $\mathrm{N}$ & 262 \\
\hline Hypothesis Supported? & $\mathrm{H} 5=$ Yes; H6 $=$ Yes \\
\hline$* \mathrm{p}<0.10 ; * * \mathrm{p}<0.05 ; * * * \mathrm{p}<0.01 ; * * * * \mathrm{p}<0.001$ \\
\hline
\end{tabular}

Table 4. Results of regression analysis for share knowledge behavior

\begin{tabular}{|l|l|}
\hline \multicolumn{1}{|c|}{$\begin{array}{c}\text { Independent } \\
\text { Variable }\end{array}$} & \multicolumn{1}{|c|}{$\begin{array}{c}\text { Attitude to Share } \\
\text { Knowledge }\end{array}$} \\
\hline Intercept & $1.302^{* * * *}$ \\
\hline $\begin{array}{l}\text { Intention to share } \\
\text { Knowledge }\end{array}$ & $0.581 * * * *$ \\
\hline $\begin{array}{l}\text { Use of ICT that supports } \\
\text { transmission of information }\end{array}$ & $0.037 * * * *$ \\
\hline R-Square & 0.3751 \\
\hline F & 53.22 \\
\hline Prob. (F) & $<.0001$ \\
\hline $\mathrm{N}$ & 262 \\
\hline Hypothesis Supported? & $\mathrm{H7}=\mathrm{Yes} ; \mathrm{H} 8=$ Yes \\
\hline$* \mathrm{p}<0.10 ; * * \mathrm{p}<0.05 ; * * * \mathrm{p}<0.01 ; * * * * \mathrm{p}<0.001$ \\
\hline
\end{tabular}

\section{Discussion}

We did not find any support for hypothesis 1 . The literature revealed inconsistent findings concerning factors that motivate employees to share their knowledge in other types of organizational environments. Motivational factors, such as rewards, significantly affect employees' attitudes and intentions [37]. Rewards often encouraged knowledge sharing [29]. However, there are studies that did not find any effect of expected rewards on individuals' attitude toward knowledge sharing [8], and the present study supports this finding. Performance-based pay or rewards have no relationship, or even a negative relationship, between rewards and performance [8, 36]. In fact, these studies demonstrated that monetary rewards, promotions, or punitive measures will not encourage any type of knowledge sharing and may be construed as coercion [40]. Thus, the findings on the relationship between expected rewards and knowledge sharing remain inconclusive. This is certainly an area for future research.

We found supports for both hypotheses 2 and 3. The results of this study show that expected associations were significant positive predictors of employee attitudes to share knowledge in homeland security. We also found that expected contributions were significant positive predictors of employee attitudes toward knowledge sharing and indicated that participants with higher expected contributions and associations tended to have higher attitudes to share knowledge. These results are consistent with previous studies $[7,8,10,37,55]$ and indicate that individuals believe through their knowledge sharing contributions, they could improve relationships with other employees, developing stronger attitudes and intentions toward knowledge sharing, resulting in positive knowledge sharing behaviors.

Inconsistencies exist in previous studies concerning the importance and requirement for trust in knowledge sharing. Studies indicate that trust is considered a key influencer of sharing behavior [46, 16]. Trust is considered as a requirement for knowledge sharing [28]. We did not propose any direct relationship between trust and knowledge sharing. We suggested and positive influence of trust on the attitude to share knowledge. The results of our study provided support for this relationship (hypothesis 4). Trust positively affected attitudes to share knowledge among the respondents of this survey.

We also found that employee's attitude toward knowledge would positively affect the employee's intention to share knowledge. The result supports the findings of previous studies that examined attitudes toward knowledge sharing and revealed that attitudes influence intentions to share knowledge [7, 8].

The results of this study indicated that an individual's positive intention toward knowledge sharing had positive influence on knowledge sharing behavior, thus providing support for hypothesis 6 . This reinforces the findings from earlier studies that support the positive effect of intention on knowledge sharing behavior $[8,44,53,30]$.

We found support for the effect of ICT on intention to share knowledge and knowledge sharing behavior. ICT that supports information processing strengthens knowledge sharing intention while ICT that supports transmission of information facilitates knowledge sharing behavior. These are interesting findings of this study. As suggested in MST, communication processes can be effective when individuals are engaged in two processes: information transmission and information processing [17]. Information transmission involves "preparing information for transmission, transmitting it through a medium, and receiving information through a 
medium”, while information processing involves "understanding the meaning information and integrating it into a mental model” [17] (p. 576). The focus of information processing is within individuals whereas that of information transmission is among individuals [17]. Thus, we suggested that ICT that supports information processing would have a positive influence on the intention to share knowledge while ICT that supports transmission of information would affect knowledge sharing behavior in a positive manner. The findings of this study provide support for both relationships (i.e. hypotheses 6 and 8).

\section{Limitations of the study}

An important limitation of this study is its use of a web-based survey to collect data. A respondent may not remain fully engaged and the response rate may be low in poorly designed web-based surveys. We took care to address these limitations in our study.

The survey participants were restricted to employees in a single United States federal government agency with a primary mission of homeland security. The findings may not be generalizable or relevant for other government agencies.

The third limitation of the study involved potential respondents' concern with the organizational climate. Because of the challenging political climate, individuals appeared to suspect ulterior motives behind the questionnaire, and some were reluctant to take part in the study at all. Additionally, organizational missions - preventing terrorism and enhancing security, managing national borders, securing cyberspace, ensuring disaster resilience, and administering immigration laws-may have influenced respondents' actual knowledge sharing behavior. Respondent concerns can arise despite assurances and measures taken to guarantee the anonymity and privacy of the data.

\section{Implications}

\subsection{Implications for practice}

In general, the results from this study could be used to inform employees of what knowledge sharing is, its importance, and the benefits of sharing. From there, employees can be informed or trained on how to share knowledge, with a focus on the use of various types of technology that can be used for knowledge sharing effectiveness and efficiency.

In addition, the findings of the present study indicated the effects of ICT usage on knowledge sharing intention. While the availability of technology or its use does not automatically guarantee successful knowledge sharing behavior, the findings in this study confirm the importance of individual employee's use of technology in sharing knowledge and lend support to informed decisionmaking toward adopting useful types of technology to facilitate collaboration and knowledge sharing.

\subsection{Implications for Research}

This study is significant in that it contributes to the body of knowledge on information systems, knowledge sharing, human behavior, public sector, and federal government agencies, which is often overlooked and under- investigated.

Regarding public sector government organizations, this study demonstrated that expected rewards such as monetary rewards, promotions, do not encourage or discourage knowledge sharing. However, one's expected contribution, their confidence in their ability to share; expected associations with others or ability to improve relationships; and the use and type of technology available for knowledge sharing affect individuals' attitudes and intentions toward knowledge sharing.

This may result in the findings not being immediately generalizable or relevant for other government agencies. Even within the federal government, the results could be expected to differ according to agency [33] and conducting similar studies in other agencies in the federal government, or different types of organizations and sectors may result in improved generalizability [33]. The sample of our study was split evenly between participants from the National Capital Region (NCR) ( $\mathrm{n}=131$, $48.3 \%$ ) and those outside of the NCR ( $\mathrm{n}=131$, $48.3 \%$ ). Thus, our findings have some degree of internal validity within the government agency that we studied. However, we acknowledge that future studies should be conducted with other government agencies to establish the generalizability of our findings.

\section{Conclusions}

Most studies on knowledge sharing have been conducted in the private sector or on foreign governments. This study was conducted in an oftenoverlooked organization type-an agency within the U.S. federal government, a large, diverse, and previously unstudied context. Therefore, the study expands on existing literature by investigating employee attitudes, intentions, and knowledge sharing behaviors, rust, or the lack of trust between potential sharers of knowledge and the use of 
technology to facilitate knowledge sharing.

This study is a step towards a greater understanding of the factors, such as technology, which affects how the intention to share knowledge influences the actual knowledge sharing behavior of employees in homeland security. The use of technology makes it possible to share massive amounts of knowledge in many ways, with multitudes of people. It is through the sharing of knowledge that problems are solved, ideas are formed, and new innovations emerge.

\section{References}

[1] I. Ajzen, "The theory of planned behavior," Organizational behavior and human decision processes, vol. 50, no. 3 1991, pp. 179-211.

[2] I. Ajzen, and M. Fishbein, Understanding attitudes and predicting social behavior, 1980.

[3] I. Ajzen, and M. Fishbein, The influence of attitudes on behavior, 2005.

[4] M. Alavi, T.R. Kayworth, and D.E. Leidner, “An empirical examination of the influence of organizational culture on knowledge management practices," Journal of Management Information Systems, vol. 22, no. 3. 2006, pp. 191-224.

[5] I. Arpaci and M. Baloğlu, "The impact of cultural collectivism on knowledge sharing among information technology majoring undergraduates," Computers in Human Behavior, vol. 56, 2016, pp. 65-71.

[6] A. Bandura, "The explanatory and predictive scope of self- efficacy theory," Journal of Social and Clinical Psychology, vol. 4, no. 3. 1986, pp. 359-373.

[7] G.W. Bock. and Y.G. Kim, "Breaking the myths of rewards: An exploratory study of attitudes about knowledge sharing," Information Resources Management Journal, vol. 14, 2001, pp. 14-21.

[8] G.W. Bock, R.W. Zmud, Y.G. Kim, and J.N. Lee, "Behavioral intention formation in knowledge sharing: Examining the roles of extrinsic motivators, socialpsychological forces, and organizational climate," MIS Quarterly, vol. 29, no. 1. 2005, pp. 87-112.

[9] G. Casimir, N.K.Y. Ng, and L.P. Cheng, "Using IT to share knowledge and the TRA," Journal of Knowledge Management, vol. 16, no. 3. 2012, pp. 461-479. https://doi.org/10.1108/13673271211238779

[10] C.M. Chiu, M.H. Hsu, and E.T. Wang, "Understanding knowledge sharing in virtual communities: An integration of social capital and social cognitive theories," Decision Support Systems, vol. 42, no. 3. 2006, pp. 1872-1888.

[11] J. Cohen, “A power primer,” Psychological Bulletin, vol. 112, no. 1. 1992, pp. 155-159.

[12] D. Constant, S. Kiesler, and L. Sproull, "What's mine is ours, or is it? A study of attitudes about information sharing," Information Systems Research, vol. 5, no. 4. 1994, pp. 400- 421.

[13] J.W. Creswell, Research design: Qualitative, quantitative, and mixed methods approaches. Thousand Oaks, CA: Sage, 2014.
[14] L.J. Cronbach and P. E. Meehl, "Construct validity in psychological tests,” Psychological Bulletin, vol. 52, no. 4. 1955, pp. 281-302.

[15] F.D. Davis, "Perceived usefulness, perceived ease of use, and user acceptance of information technology," MIS Quarterly, vol. 13, no. 3. 1989, pp. 319-339.

[16] S.S. Dawes, A.M. Cresswell, and T.A. Pardo, "From" need to know" to" need to share": Tangled problems, information boundaries, and the building of public sector knowledge networks," Public Administration Review, vol. 69, no. 3. 2009, pp. 391-402.

[17] A.R. Dennis, R.M. Fuller, and J.S. Valacich, "Media, tasks, and communication processes: A theory of media synchronicity," MIS quarterly, vol. 32, no. 3. 2008, pp. 575- 600 .

[18] e-Government Act of 2002. Pub. L. No. 107-347, 116 Stat. 2899, 44 U.S.C. § 101, H.R. 2458/S. 803., 2002.

[19] Executive Office of the President: Office of Management and Budget [OMB]. Transmittal Memorandum \#4: Management of Federal Information Resources (OMB Circular A-130). Washington, DC: Author, 2000, November 28.

[20] Executive Office of the President: Office of Management and Budget [OMB]. President's memorandum on transparency and open government-Interagency collaboration (OMB Memorandum M-09-12). Washington, DC: John P. Holdren, Peter Orszag, and Paul F. Prouty., 2009, February 26.

[21] M. Fishbein and I. Ajzen, “Attitudes and voting behavior: An application of the theory of reasoned action,” Progress in Applied Social Psychology, vol. 1, 1981, pp. 253-313.

[22] F.J. Fowler, "Improving survey questions: Design and evaluation,” Applied Social Research Methods Series, vol. 38, no. 3, 1991, pp. 392-397.

[23] D. George and P. Mallery, SPSS for Windows step by step: A simple guide and reference, 11.0 update (14th ed.). Boston, MA: Allyn and Bacon, 2016.

[24] B. Gupta, "The effect of expected benefit and perceived cost on employees' knowledge sharing behavior: A study of IT employees in India," Organizations and Markets in Emerging Economies, vol. 3, no. 1. 2012, pp. 8-20.

[25] Homeland Security Act Amendments. Pub. L. 108-7, Stat. 526, 6 U.S.C. §117. 301., 2003.

[26] Homeland Security Act. . Pub. L. 107-296, Stat. 2135, 6 U.S.C §116., 2002.

[27] Homeland Security Information Sharing Act. Pub. L. 107- 296, Stat. 2252, 6 U.S.C. §481(a)., 2002.

[28] C.L. Hsu and J.C.C. Lin, "Acceptance of blog usage: The roles of technology acceptance, social influence, and knowledge sharing motivation," Information \& Management, vol. 45, no. 1. 2008, pp. 65-74.

[29] M.H. Hsu, T.L. Ju, C.H. Yen, and C.M. Chang, "Knowledge sharing behavior in virtual communities: The relationship between trust, self-efficacy, and outcome expectations," International Journal of Human Computer Studies, vol. 65, no. 2. 2007, pp. 153-169.

[30] A. Jolaee, K. Md Nor, N. Khani, and R. Md Yusoff, "Factors affecting knowledge sharing intention among 
academic staff,” International Journal of Educational Management, vol. 28, no. 4. 2014, pp. 413-431.

[31] H. H. Kelley and J. W. Thibaut, J. W. Interpersonal relations: A theory of interdependence. John Wiley \& Sons, 1978.

[32] T. Khalil, K. Atieh, A.U. Mohammad, and F. Bagdadlian, "Examining the social and technical factors influencing schoolteachers' knowledge sharing intentions in a Teachers Online Professional Community," Electronic Journal of Knowledge Management, vol. 12, no. 3. 2014, pp. 157.

[33] S. Kim and H. Lee, "Employee knowledge sharing capabilities in public \& private organizations: Does organizational context matter?" Proceedings of the 38th Annual Hawaii International Conference on System Sciences, 2005.

[34] R. Kling and R. Lamb, "IT and organizational change in digital economies: A socio-technical approach," ACM SIGCAS Computers and Society, 29(3), 1999, pp. 17-25.

[35] H. Lee and B. Choi, B., "Knowledge management enablers, processes, and organizational performance: An integrative view and empirical examination," Journal of Management Information System, 2003, pp. 179-228.

[36] J. Liebowitz, Social networking: The essence of innovation. Lanham, MD: Scarecrow Press, 2007.

[37] H.F. Lin, "Impact of organizational support on organizational intention to facilitate knowledge sharing," Knowledge Management Research \& Practice, vol. 4, 2006, pp. 26-35.

[38] A. Majchrzak and S.L. Jarvenpaa, "Information security in cross-collaborative knowledge work," $E$ CO Emergence, vol. 6, no. 4. 2004, pp. 4-14.

[39] S. Milovanovic, "Knowledge sharing between users and information specialists: Role of trust," Economics and Organization, vol. 3, no. 1. 2006, pp. 51-58.

[40] S. Ozlati, Motivation, trust, leadership, and technology: Predictors of knowledge sharing behavior in the workplace (Doctoral dissertation), 2012.

[41] T.A. Pardo, A.M. Cresswell, F. Thompson and J. Zhang, "Knowledge sharing in cross-boundary information system development in the public sector," Information Technology and Management, vol. 7, no. 4. 2006, pp. 293-313.

[42] A. Riege, "Three-dozen knowledge-sharing barriers managers must consider," Journal of Knowledge Management, vol. 9, no. 3. 2005, pp. 18-35.

[43] R. Ruggles, "The state of the notion," California Management Review, vol. 40, no. 3. 1998, pp. 80-89.

[44] S. Ryu, S.H. Ho, and I. Han, I., "Knowledge sharing behavior of physicians in hospitals," Expert Systems with Applications, vol. 25, no. 1. 2003, pp. 113-122.

[45] N.J. Salkind, Exploring research (6th ed.). Upper Saddle River, NJ: Pearson Education, 2006

[46] I. Seba, J. Rowley, and S. Lambert, "Factors affecting attitudes and intentions towards knowledge sharing in the Dubai Police Force," International Journal of Information Management, vol. 32, no. 4. 2012, pp. 372-380.

[47] J.P. Stevens, Applied multivariate statistics for the social sciences (6th ed.). Mahwah, NJ: Routledge
Academic, 2016.

[48] D.W. Straub, "Validating instruments in MIS research," MIS Quarterly, vol. 13, no. 2. 1989, pp. 147-170.

[49] D.W. Straub, M. Boudreau, and D. Gefen, "Validation guidelines for IS positivist research," Communications of the Association for Information Systems, vol. 13, 2004, pp. 380- 427.

[50] F.O. Sveen, E. Rich, and M. Jager, “Overcoming organizational challenges to secure knowledge management,” Journal Information Systems Frontiers, vol. 9, no. 5. 2007, pp. 481-492.

[51] C.N.L. Tan, Y.H. Lye, T.H. Ng, and Y.S. Lim, "Motivational factors in influencing knowledge sharing among banks in Malaysia," International Research Journal of Finance and Economics, vol. 44, 2010, pp. 191-201.

[52] O. Tha and K. Khet, "Individual knowledge sharing behavior in organizations," Proceedings of the 17th Americas Conference on Information Systems, Detroit, MI, 2011.

[53] Z. Tohidinia and M. Mosakhani, "Knowledge sharing behavior and its predictors," Industrial Management Data Systems, vol. 110, no. 4. 2010, pp. 611-631. https://doi.org/10.1108/02635571011039052

[54] W.M.K. Trochim and J.P. Donnelly, The research methods knowledge base (3rd ed.; pp. 56-65). Mason, OH: Atomic Dog, 2008.

[55] H.T. Tsai, H. T. and R.P. Bagozzi, "Contribution behavior in virtual communities: Cognitive, emotional, and social influences," MIS Quarterly, vol. 38, no. 1. 2014, pp. 143- 164.

[56] M.T. Tsai, K.S. Chen, and J.L. Chien, "The factors impact of knowledge sharing intentions: The theory of reasoned action perspective," Quality \& Quantity, vol. 46, no. 89. 2012, pp. 1479-1491. https://doi.org/10.1007/s11135-011-9462-9

[57] T. Tuten, "Conducting online surveys," In: S. D. Gosling and J. A. Johnson (Eds.), Advancing methods for conducting online behavioral research (pp.179192). Washington, DC: American Psychological Association, 2010.

[58] United States Department of Homeland Security [DHS]. Department of Homeland Security Organizations Office of the Secretary, 2019.

[59] United States Department of Homeland Security. Appendix B: Multi-modal access plan for the Department of Homeland Security pursuant to E.O. 13693, Planning for Federal Sustainability in the Next Decade, 2016.

[60] United States Government Accountability Office [GAO]. Information Sharing: DHS Has Demonstrated Leadership and Progress, but Additional Actions Could Help Sustain and Strengthen Efforts (GAO-12809). Washington, DC., 2012, September 18.

[61] A. Usoro, M.W. Sharratt, E. Tsui and S. Shekhar, "Trust as an antecedent to knowledge sharing in virtual communities of practice," Knowledge Management Research \& Practice, vol. 5, no. 3. 2007, pp. 199-212. 